\title{
Implementation of an interprofessional collaboration in practice program: a feasibility study using social network analysis
}

Linda C. Smit ${ }^{*}$ (D), Jeroen Dikken², Nienke M. Moolenaar ${ }^{3}$, Marieke J. Schuurmans ${ }^{4}$, Niek J. de Wit ${ }^{5}$ and Nienke Bleijenberg ${ }^{1,6}$

\begin{abstract}
Background: Due to multimorbidity and geriatric problems, older people often require both psychosocial and medical care. Collaboration between medical and social professionals is a prerequisite to deliver high-quality care for community-living older people. Effective, safe, and person-centered care relies on skilled interprofessional collaboration and practice. Little is known about interprofessional education to increase interprofessional collaboration in practice (IPCP) in the context of community care for older people. This study examines the feasibility of the implementation of an IPCP program in three community districts and determines its potential to increase interprofessional collaboration between primary healthcare professionals caring for older people.

Method: A feasibility study was conducted to determine the acceptability and feasibility of data collection and analysis regarding interprofessional collaboration in network development. A questionnaire was used to measure the learning experience and the acquisition of knowledge and skills regarding the program. Network development was assessed by distributing a social network survey among professionals attending the program as well as professionals not attending the program at baseline and 5.5 months after. Network development was determined by calculating the number, reciprocity, value, and diversity of contacts between professionals using social network analysis.

Results: The IPCP program was found to be instructive and the knowledge and skills gained were applicable in practice. Social network analysis was feasible to conduct and revealed a spill-over effect regarding network development. Program participants, as well as non-program participants, had larger, more reciprocal, and more diverse interprofessional networks than they did before the program.

Conclusions: This study showed the feasibility of implementing an IPCP program in terms of acceptability, feasibility of data collection, and social network analysis to measure network development, and indicated potential to increase interprofessional collaboration between primary healthcare professionals. Both program participants and non-program participants developed a larger, more collaborative, and diverse interprofessional network.
\end{abstract}

Keywords: Interprofessional education, Interprofessional collaboration, Social Network Analysis, Primary care

\footnotetext{
*Correspondence: linda.smit@hu.nl

${ }^{1}$ Research Centre for Healthy and Sustainable Living, University of Applied

Sciences Utrecht, 3584 CS Utrecht, The Netherlands

Full list of author information is available at the end of the article
}

(c) The Author(s). 2021 Open Access This article is licensed under a Creative Commons Attribution 4.0 International License, which permits use, sharing, adaptation, distribution and reproduction in any medium or format, as long as you give appropriate credit to the original author(s) and the source, provide a link to the Creative Commons licence, and indicate if changes were made. The images or other third party material in this article are included in the article's Creative Commons licence, unless indicated otherwise in a credit line to the material. If material is not included in the article's Creative Commons licence and your intended use is not permitted by statutory regulation or exceeds the permitted use, you will need to obtain permission directly from the copyright holder. To view a copy of this licence, visit http://creativecommons.org/licenses/by/4.0/ The Creative Commons Public Domain Dedication waiver (http://creativecommons.org/publicdomain/zero/1.0/) applies to the data made available in this article, unless otherwise stated in a credit line to the data. 


\section{Introduction}

With rapid population aging, the provision of care to older people with complex health issues resulting from multimorbidity and geriatric problems is a major challenge [1]. In the Netherlands, two-thirds of people aged 65 years and older are experiencing multimorbidity and geriatric problems. It is estimated that by $2050,33.2 \%$ of the population will be aged 60 years and older [2]. Currently, $94 \%$ of older people in The Netherlands live at home, and their complex conditions need medical- and social-care solutions. For these solutions, interprofessional collaboration in practice (IPCP) between healthcare professionals is essential $[3,4]$.

Interprofessional collaboration has been defined as follows: an evolving interpersonal process, involving a diverse team of healthcare and other community providers who interdependently engage in frequent communication and shared decision-making, for the purposes of providing optimal health and social care services to community-living older adults and their families [5]. IPCP in healthcare occurs when multiple health workers from different professional backgrounds provide comprehensive services by working with patients, their families, caregivers, and communities to deliver the highest quality of care across settings [1]. Community care, however, is often provided by a heterogeneous workforce consisting of professionals by different levels of education working in different organizational structures that may hamper the ability to collaborate effectively [6, 7]. Interprofessional education (IPE) can support healthcare teams by utilizing the individual skills of their members, sharing case management, providing better health services to patients and the community, and improving patient outcomes $[1,8,9]$. IPE occurs when two or more professionals learn with, from, and about each other to improve collaboration and quality care [10]. Most IPE focuses on academic settings, and acute, and long-term care sectors [11]. Little is known about IPE to enhance interprofessional collaboration in practice for community-living older people $[6,12]$. A pilot IPE program for general practitioners (GPs) and practice nurses from different community districts evaluated the effect of the IPE program for these professionals and reported that an IPE for professionals with different educational backgrounds (GPs and practice nurses) is feasible and adds value to the redefining of tasks and responsibilities among GPs and practice nurses [13]. However, studies examine the implementation of an IPCP program for primary care healthcare professionals from the medical and social domains are lacking. Therefore, a feasibility study was initiated to examine the implementation of an IPCP program [14] for healthcare professionals from the medical and social domains to enhance interprofessional collaboration. The aim of this study is to examine the feasibility of the implementation of an IPCP program in three community districts to determine its potential to increase interprofessional collaboration between primary healthcare professionals caring for older people. The feasibility objectives were as follows: (1) to determine the acceptability of the IPCP program, (2) to determine whether data can be collected during the implementation of an IPCP program to construct networks in a meaningful way, and (3) to examine the possibility of measuring network development in terms of the number, reciprocity, value, and diversity of contacts between healthcare professionals in three community districts.

\section{Method}

\section{Study design}

We performed a pre-post study to examine the feasibility of implementing a previously developed IPCP program in three community districts. Figure 1 provides an overview of the study design and elements of the IPCP program.

\section{Participants and setting}

Participants who were attending the IPCP program ("programme participants") were primary healthcare professionals delivering care to community-living older people in three community districts in the city of Utrecht (350,000 inhabitants), the Netherlands. Participants included GPs, practice nurses, district nurses, social workers, physiotherapists, and pharmacists. In addition, "non-programme participants" were included. Nonprogram participants were professionals who did not participate in the IPCP program but only participated with consent in the social network data collection.

\section{IPCP program}

The IPCP program was developed to enhance interprofessional collaboration among primary healthcare providers and was co-created by professionals from clinical practice, education, and research. The developmental process of the IPCP program has been described elsewhere [14]. A development team discussed the competencies of interprofessional collaboration [15], resulting in three main themes as the basis for the IPCP program, namely, role identity, shared vision, and communication. Based on these themes, learning objectives and activities were developed. The IPCP program included sixteen study hours and covered 6 weeks, and consisted of face-to-face meetings, online learning, and on-the-job learning (see Fig. 1). This blended learning approach was chosen to fit the diverse target group and for its positive effect on knowledge acquisition among health professionals [16]. A partner in developing the IPCP program, (as described elsewhere) [14], which is also an organization that offers educational training and guidance on collaboration in healthcare practices in the community, acted as independent coordinator in recruiting participants. Information leaflets were 


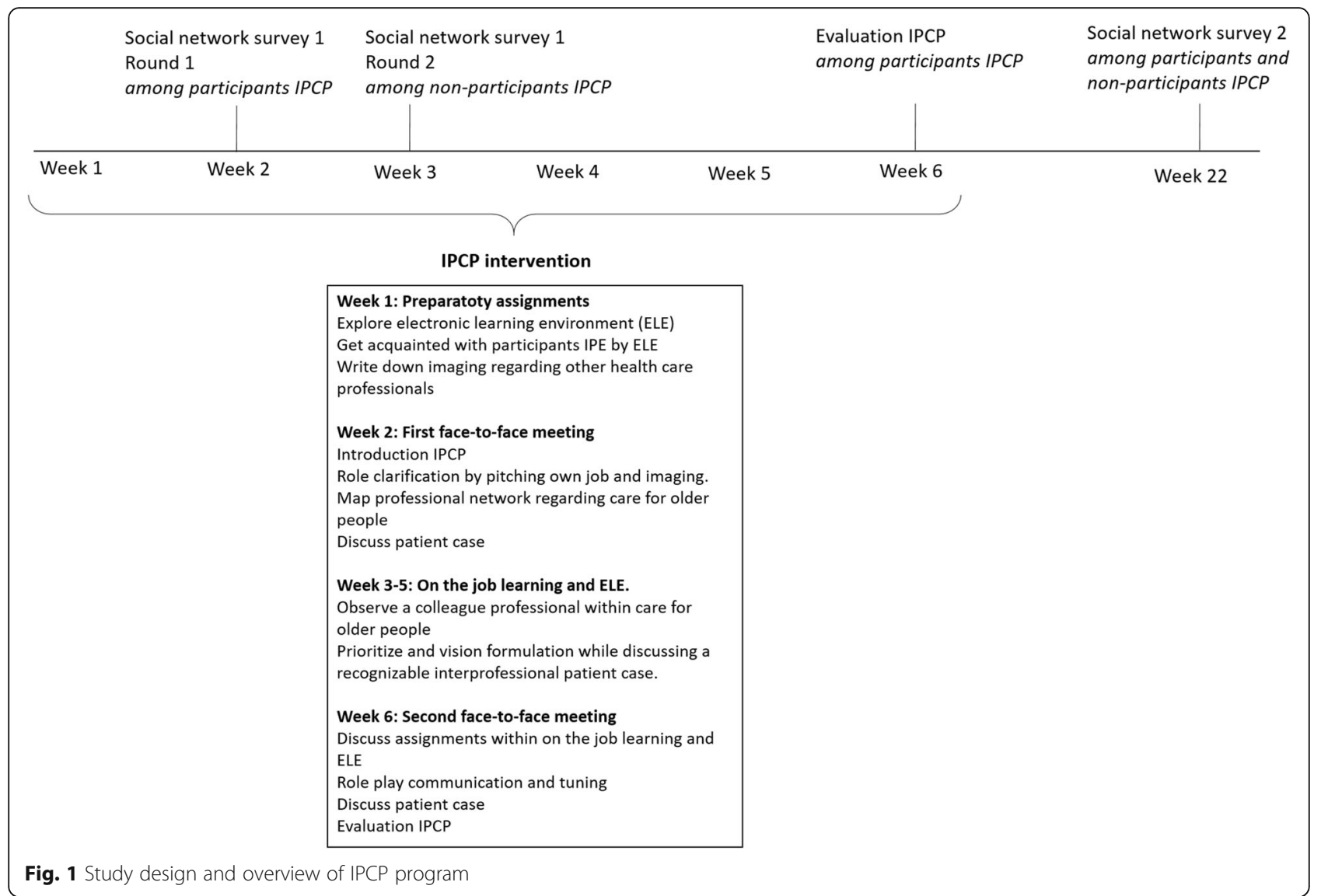

provided by the organization to the medical and social healthcare professionals as well as the regional coordinators. Professionals in the IPCP program participated voluntarily and free of costs because of the nature of the IPCP program as a feasibility study.

\section{Feasibility outcomes}

The acceptability of the IPCP program was defined as (1) the views on the learning experience and its interprofessional nature, and (2) the acquisition of knowledge and skills linked to interprofessional collaboration indicated by the program participants [17].

The feasibility of data collection and analysis was determined by collecting and measuring network development regarding the interprofessional collaboration between professionals working in the same district. To compare the community's collaboration networks, we assessed network development by the number of contacts with other professionals, the extent to which contacts are reciprocal, the diversity of contacts, and the perceived value of contacts.

\section{Data collection and measurement}

The acceptability of the IPCP program was, after delivery, evaluated among 22 program participants using a self-reported questionnaire. The questionnaire, originally developed by the Expertise Center for Education and Training located at the Utrecht Medical Center (The Netherlands), was adapted to the context of IPCP and included two concepts based on the adapted framework of Kirkpatrick for interprofessional education [17]. First, participants' satisfaction with the program was assessed by asking about perceptions of the content, organization, teaching, materials, and online environment of the IPCP program. Second, the applicability of the IPCP content was evaluated by asking about perceptions in acting toward fellow professionals and in applying knowledge and skills gained from the program. In total, the questionnaire involved 20 questions in which several measurement scales were used including $1-10$ scales (4 questions, with a higher score indicating a higher appreciation), yes-a little-no scales (11 questions), and insufficient, sufficient, more-than-sufficient, good, very-good scales (5 questions).

Interprofessional collaboration was measured among program participants $(N=22)$ and non-program participants $\left(N=33 ; N_{\text {total }}=55\right)$ using a social network survey. The IPCP program was delivered to a maximum of ten professionals in each district. The nature of the IPCP program was to enhance interprofessional collaboration in which we expect a spill-over effect of the IPCP 
program. To capture this spill-over effect, non-program participants were also included. A social network survey was administered at two-time points (see Fig. 1). At both time points, we posed the following network question: "out of all the primary healthcare professionals in the community, with whom do you collaborate regarding care for community-living older people?" [18]. At time point 1 , data were collected in two rounds.

\section{Round 1-Collecting data from IPCP program participants (ring 1)}

The professionals who participated in the IPCP program (called "the first ring" of network members) were asked to provide a list of all primary healthcare professionals with whom they collaborate with about care for community-living older people [18]. In addition, we asked the program participants to indicate the value of these contacts on a scale of 1-10. Using these data, we visualized ego-networks for each participant (the socalled "ego") and his/her contacts (the so-called "alters"). These contacts formed "the second ring" of network members surrounding each ego $[19,20]$. Figure 2 provides a diagrammatic representation of the network theory and data collection.

\section{Round 2-Collecting data from the program participants' contacts in the district (ring 2)}

Using the data collected in the first round, a list of names including all program participants (egos) and their nominations (alters) was created, resulting in a single, comprehensive list of potential healthcare professionals who may collaborate with each other in each community district. Subsequently, all professionals from this list were invited to complete, and thereby gave their consent for, the survey (see Fig. 2). We asked the participants to indicate with whom they collaborated in regard to care for community-living older people and how they value each of their contacts on a scale (1-10).

At the second time point, we again used this comprehensive list of names to delineate the community's collaboration networks.

In each community district, between $27 \%$ and $40 \%$ of all nominated healthcare professionals responded and consented to the social network survey during round 2 of the data collection. The response rate also indicates the unit non-response, which is defined as completely missing for healthcare professionals for whom all outgoing contacts of the professional are missing but not the incoming contacts. This is because professionals who did respond also nominated the non-responding professionals as professionals with whom they work [21]. The collected data, therefore, were divided into three data categories: (1) program participants, (2) nonprogram participants, and (3) non-consented professionals, further described as rings 1,2 , and 3 .

\section{Network development Number of contacts}

The number of contacts was calculated for each professional as the number of professionals with whom the participant indicated as collaborating with regarding care for older people (out-degree) [19]. A social network diagram was used to visualize the number of contacts between professionals. The professionals were visualized as colored squares of which the color indicates the ring 1 , 2 , or 3 , in which the professionals were categorized. To compare the networks across community districts, we also calculated the network measures average degree of

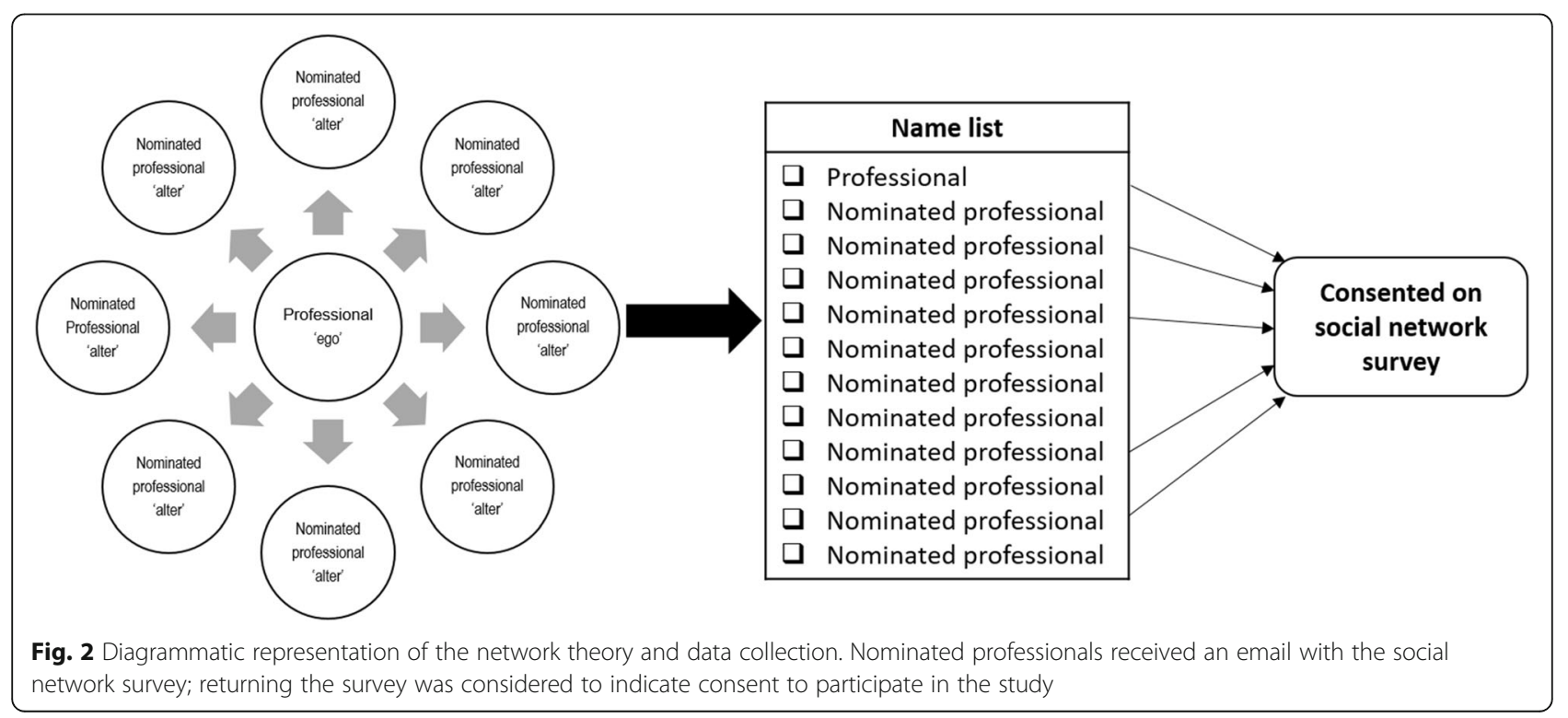


contacts, density, and E-I index [19]. The average degree of contacts was calculated as the average out-degree for each community district. The network's density was calculated as the proportion of existing relationships out of the maximum number of relationships possible in the network. The denser the network, the more professionals collaborate with one another. The value of density varied between 0 (no relations in the network) and 1 (all actors are connected to each other). Finally, the E-I index was calculated for each network to determine whether ring 1 and ring 2 differed in their choice of alters. For instance, did ring 1 mainly increase collaboration with other ring 1 participants, or did they also increase collaboration with ring 2 members? And did ring 2 members also increase interprofessional collaboration, even though they did not participate directly in the IPCP program? The E-I index ranges from -1 (all contacts are internal to the group) to +1 (all contacts are external to the group).

\section{Reciprocity of contacts}

Reciprocity of contacts was calculated as the ratio of the number of pairs who shared a reciprocal network connection, (i.e., they both chose the other to collaborate with) relative to the number of pairs within any given contact. A high level of reciprocity reflects a high level of reciprocal collaboration between professionals in a district [19]. Reciprocal contacts of the professionals were visualized in a social network diagram displaying reciprocal and onesided contacts between professionals for each district.

\section{Diversity of contacts}

Diversity of contacts was calculated as the extent to which contacts in the community district transcend the different backgrounds in disciplines (see Table 1) $[18,19]$. The score for diversity in relationships can vary between 0 and 1 . A high score indicates that the healthcare professional collaborates with healthcare professionals from a wide variety of disciplines (heterogeneity) while a low score indicates that the healthcare professional mainly chooses to collaborate with others from the same discipline (homogeneity).

\section{Value of contacts}

For each professional, we calculated the average of the value that $\mathrm{s} / \mathrm{he}$ placed on each network contact. The score for the value of contact can vary between 1 and 10. A high score indicated that healthcare professionals highly appreciated their collaboration with that specific professional while a low score indicated a low appreciation for the collaboration.

\section{Sample size}

During the development process of the IPCP program, it was decided to include seven to ten program
Table 1 Definition and formula for diversity of contacts

Heterogeneity indicates, per healthcare professional; $i$, the degree of the number of relationships outside their own discipline in relation to the number of all possible different disciplines with which they are in contact. The number of times healthcare professional; $i$, has been chosen by the other healthcare professionals is considered (in-degree), because this parameter has a higher reliability with reality than the relationships indicated by the healthcare professional themselves (outdegree). Diversity is thus determined on the basis of two components:

$P_{\mathrm{iR}}$, the proportion of healthcare professions i's relationships with members of other disciplines, $R_{\text {divi, }}$ regarding all relationships of healthcare professions $i R_{\mathrm{i}}$; and $D_{\mathrm{iD}}$, the number of diverse disciplines with which healthcare professions; $i$, has contact outside of his own discipline, $D_{\text {divi }}$ regarding all disciplines within the network minus the own discipline of healthcare professions, $i D_{\mathrm{i}}$ :

$P_{\mathrm{iR}}=\left(R_{\mathrm{i}}-R_{\mathrm{divi}}\right) / R_{\mathrm{i}}$

$D_{\mathrm{iD}}=D_{\text {divi }} / D_{\mathrm{i}}$

For every healthcare professional within the network, diversity is defined as:

$H_{\mathrm{i}}=\sum \mathrm{P}_{\mathrm{iR}} \times D_{\mathrm{iD}}$

When a healthcare professional has relationships within all professionals, and as many professionals speak outside their own professionals as within their own professional, then $P_{\mathrm{iR}}=0.5$ and $D_{\mathrm{iD}}=1$. The diversity of relationships for this healthcare professional, $H_{\mathrm{i}}$, is $0.5 / 1=0.5$. The score for diversity in relationships can vary between 0 and 1 .

participants per community district to achieve a high degree of interaction between professionals during the implementation of the program. The interaction between professionals was important to address the three main themes of the program, role identity, shared vision, and communication. A convenience sample of 22 program participants participated and consented to participate in this study. Non-program participants were included as well in determining the network development of each community district. Due to scattered healthcare organizations in the districts, it was very difficult to generate a name roster of all professionals per community district. By combining the snowball method (using the program participants) and a fixed-list selection of names, we obtained access to each whole community of healthcare professionals of which 33 non-program participants consented to participate in our study [19].

\section{Social network analysis}

All social network measures were calculated and analyzed using UCINET 6.6, a network analysis program used for descriptive and inferential network statistics [20]. To determine a significant increase in the value and diversity of contacts, a paired $T$ test was performed using the SPSS software version 24 for Windows (IBM SPSS Statistics, IBM Corporation, Armonk, NY).

\section{Results}

Twenty-two participants participated in the IPCP program, and a total of 55 program and non-program participants were included in the data analysis (see Table 2). 
Table 2 Healthcare professionals included in the study $(N=55)$

\begin{tabular}{|c|c|c|c|c|c|c|c|c|}
\hline & \multicolumn{2}{|c|}{ Total } & \multicolumn{2}{|c|}{ District 1} & \multicolumn{2}{|c|}{ District 2} & \multicolumn{2}{|c|}{ District 3} \\
\hline Program participants & \multicolumn{2}{|c|}{$N=22$} & \multicolumn{2}{|c|}{$N=7$} & \multicolumn{2}{|c|}{$N=8$} & \multicolumn{2}{|c|}{$N=7$} \\
\hline General practitioner, $n(\%)$ & 3 & 13.6 & 1 & 14.3 & 1 & 12.5 & 1 & 14.3 \\
\hline Practice nurse, $n(\%)$ & 1 & 4.6 & 1 & 14.3 & 0 & 0.0 & 0 & 0.0 \\
\hline Physiotherapist, n (\%) & 1 & 4.6 & 0 & 0 & 1 & 12.5 & 0 & 0.0 \\
\hline Social care worker, $n$ (\%) & 5 & 22.7 & 1 & 14.3 & 2 & 25.0 & 2 & 28.6 \\
\hline Social care prescriber, $n(\%)$ & 4 & 18.2 & 2 & 28.6 & 1 & 12.5 & 1 & 14.3 \\
\hline District nurse, $n(\%)$ & 6 & 27.3 & 2 & 28.6 & 2 & 25.0 & 2 & 28.6 \\
\hline Pharmacist, $n$ (\%) & 2 & 9.1 & 0 & 0 & 1 & 12.5 & 1 & 14.3 \\
\hline Non-program participants & \multicolumn{2}{|c|}{$N=33$} & \multicolumn{2}{|c|}{$N=9$} & \multicolumn{2}{|c|}{$N=11$} & \multicolumn{2}{|c|}{$N=13$} \\
\hline General practitioner, $n(\%)$ & 5 & 15.2 & 1 & 11.1 & 1 & 9.1 & 3 & 23.1 \\
\hline Practice nurse, $n(\%)$ & 5 & 15.2 & 2 & 22.2 & 1 & 9.1 & 2 & 15.4 \\
\hline Physiotherapist, $n$ (\%) & 1 & 3.0 & 0 & 0.0 & 0 & 0.0 & 1 & 7.7 \\
\hline Social care worker, $n$ (\%) & 10 & 30.3 & 2 & 22.2 & 5 & 45.5 & 3 & 23.1 \\
\hline Social care prescriber, $n(\%)$ & 3 & 9.1 & 1 & 11.1 & 1 & 9.1 & 1 & 7.7 \\
\hline District nurse, $n(\%)$ & 4 & 12.1 & 1 & 11.1 & 1 & 9.1 & 2 & 15.4 \\
\hline Pharmacist, $n$ (\%) & 2 & 6.1 & 0 & 0.0 & 1 & 9.1 & 1 & 7.7 \\
\hline Specialist geriatric medicine, $n(\%)$ & 1 & 3.0 & 1 & 11.1 & 0 & 0.0 & 0 & 0.0 \\
\hline Dietician, $n(\%)$ & 1 & 3.0 & 1 & 11.1 & 0 & 0.0 & 0 & 0.0 \\
\hline
\end{tabular}

\section{Acceptability of the IPCP program}

The content of the IPCP program was experienced as instructive in $81 \%$ of the program participants and contributed to an enhanced interprofessional collaboration with an average score of 7.7 out of 10 (sd 1.0). Approximately $86 \%$ of the program participants indicated to act differently toward fellow professionals after attending the program, and $95 \%$ of the program participants indicated that they were able to apply the knowledge and skills of the program in practice. The participants valued the IPCP program with an average of 7.6 out of 10 (sd 1.0). For detailed information regarding the results of the questionnaire see Additional file 1.

\section{The number of contacts between professionals}

The community's collaboration networks before and after the IPCP program suggested that collaboration networks developed in each community district (see Table 3 ). In all districts, an increase in the number of contacts among the program participants was observed (ring 1). In district 1 , ring 1 reported on average 4.8 contacts before and 7.5 contacts after the IPCP program. In addition, the results suggest increased collaboration between IPCP participants and other professionals in the district that did not participate in the IPCP program (rings 2 and 3). Figure 3 visualizes the increase in contacts over time for rings 1,2 , and 3 .

In district 1, program participants reported an increase in contacts to non-program participants (from an average of 4.0 contacts before to 5.5 contacts after the IPCP program). An examination of the change in network density before and after the IPCP program suggests that in all three districts, the network density increased after the IPCP program. For example, for district 1, density increased from 34 to $51 \%$. Before the program, roughly a third of all potential connections among the healthcare professionals were actually present within a district, which increased to about half of all connections after the program. In other words, after the program, the professionals in the district tended to collaborate with more and other professionals across the district. This increase in collaboration not only held for participants in the IPCP program but also extended to non-program participants, as expressed by an increased E-I index for all districts.

\section{Reciprocity of contacts}

Program participants and non-program participants had more reciprocal contacts after the IPCP program than before, which is shown in Fig. 4. The reciprocity increased over time with $15 \%$ in district $1,2 \%$ in district 2 , and $13 \%$ in district 3 . In district 1 , for example, before the IPCP program, $49 \%$ of all potential reciprocal relationships are actually reciprocal. This number increased to almost two-thirds (64\%) after the IPCP program, indicating that the IPCP program also contributed to more sustained reciprocal collaborative efforts among the professionals. 
Table 3 Descriptive statistics

\begin{tabular}{|c|c|c|c|c|c|c|c|c|c|c|c|c|}
\hline & \multirow{2}{*}{\multicolumn{2}{|c|}{$\begin{array}{l}\text { District } 1 \\
\text { Rings } 1 \text { and } 2 \\
\end{array}$}} & \multirow{2}{*}{\multicolumn{2}{|c|}{$\begin{array}{l}\text { District } 1 \\
\text { Rings } 1,2 \text {, and } 3\end{array}$}} & \multirow{2}{*}{\multicolumn{2}{|c|}{$\begin{array}{l}\text { District } 2 \\
\text { Rings } 1 \text { and } 2 \\
\end{array}$}} & \multirow{2}{*}{\multicolumn{2}{|c|}{$\begin{array}{l}\text { District } 2 \\
\text { Rings } 1,2 \text {, and } 3 \\
\end{array}$}} & \multirow{2}{*}{\multicolumn{2}{|c|}{$\begin{array}{l}\text { District } 3 \\
\text { Rings } 1 \text { and } 2 \\
\end{array}$}} & \multirow{2}{*}{\multicolumn{2}{|c|}{$\frac{\text { District } 3}{\text { Rings } 1,2 \text {, and } 3}$}} \\
\hline & & & & & & & & & & & & \\
\hline & \multicolumn{2}{|c|}{$N=16$} & \multicolumn{2}{|c|}{$N=49$} & \multicolumn{2}{|c|}{$N=19$} & \multicolumn{2}{|c|}{$N=75$} & \multicolumn{2}{|c|}{$N=20$} & \multicolumn{2}{|c|}{$N=69$} \\
\hline & TO & T1 & TO & $\mathrm{T} 1$ & TO & $\mathrm{T} 1$ & TO & T1 & TO & T1 & TO & T1 \\
\hline \multicolumn{13}{|l|}{ Number of contacts } \\
\hline Avg. degree & 5.13 & 7.56 & 5.79 & 7.00 & 4.00 & 5.53 & 4.25 & 4.31 & 4.81 & 6.20 & 4.68 & 5.26 \\
\hline Density (\%) & 34 & 51 & 12 & 15 & 22 & 31 & 6 & 6 & 19 & 33 & 7 & 8 \\
\hline \multicolumn{13}{|l|}{ E-l index } \\
\hline \multicolumn{13}{|l|}{ Ring 1} \\
\hline Internal avg. degree & 4.8 & 7.5 & & & 3.6 & 5.1 & & & 2.0 & 3.8 & & \\
\hline Internal contacts & 26 & 38 & & & 42 & 56 & & & 8 & 14 & & \\
\hline External contacts & 32 & 44 & & & 28 & 43 & & & 38 & 51 & & \\
\hline Ring 2 & & & N.A. & & & & N.A. & & & & N.A. & \\
\hline External avg. degree & 4.0 & 5.5 & & & 2.4 & 3.7 & & & 2.3 & 3.2 & & \\
\hline Internal contacts & 20 & 22 & & & 24 & 24 & & & 102 & 98 & & \\
\hline External contacts & 32 & 44 & & & 28 & 43 & & & 38 & 51 & & \\
\hline \multicolumn{13}{|l|}{ E-l index } \\
\hline E-l index ring 1 & 0.10 & 0.07 & & & -0.20 & -0.13 & & & 0.65 & 0.57 & & \\
\hline E-l index ring 2 & 0.23 & 0.33 & & & 0.08 & 0.28 & & & -0.46 & -0.32 & & \\
\hline \multicolumn{13}{|l|}{ Collaboration } \\
\hline Reciprocity (\%) & 49 & 64 & N.A. & & 25 & 27 & N.A. & & 40 & 53 & N.A. & \\
\hline \multicolumn{13}{|l|}{ Diversity of contacts } \\
\hline Mean & 0.32 & 0.42 & & & 0.36 & 0.42 & & & 0.26 & 0.32 & & \\
\hline (SD) & $(0.17)$ & $(0.14)$ & N.A. & & $(0.15)$ & $(0.19)$ & N.A. & & $(0.17)$ & $(0.14)$ & N.A. & \\
\hline \multicolumn{13}{|l|}{ Paired $T$ test } \\
\hline t $p$ value & -4.39 & $<0.001$ & & & 2.05 & 0.055 & & & 0.91 & 0.371 & & \\
\hline \multicolumn{13}{|l|}{ Value of contacts } \\
\hline Mean & & & 7.3 & 7.7 & & & 7.6 & 7.8 & & & 7.5 & 7.5 \\
\hline (SD) & N.A. & & $(0.67)$ & $(0.47)$ & N.A. & & $(0.61)$ & $(0.65)$ & N.A. & & $(0.64)$ & $(0.58)$ \\
\hline \multicolumn{13}{|l|}{ Paired $T$ test } \\
\hline t $p$ value & & & -1.28 & 0.209 & & & -2.35 & 0.022 & & & -1.12 & 0.267 \\
\hline
\end{tabular}

\section{Diversity of contacts}

The diversity of contacts increased over time, with almost $10 \%$ (CI -0.14 to $-0.05, p$ value $<0.001$ ) in district 1 and $6 \%$ in district 2 (CI -0.13 to $-0.002, p$ value 0.055$)$ and district $3(\mathrm{CI}-0.08$ to $0.03, p$ value 0.371 ). For example, district 1 showed that of all possible diverse contacts, $32 \%$ of these were used before the IPCP program. The diversity of contacts, thus, the interprofessional collaboration between professionals, increased to $42 \%$ after the IPCP program. This finding suggests that the IPCP program contributed to a more diverse network of healthcare professionals, for both program participants as well as non-program participants.

\section{The value of contacts}

Participants from district 2 valued their collaboration with other professionals significantly more after the IPCP program $(t-2.35, \mathrm{CI}-0.33$ to $-0.03, p$ value 0.022). However, this significant increase could not be confirmed for districts $1(t-1.28$, CI -0.28 to $0.06, p$ value 0.209$)$ and $3(t-1.12, \mathrm{CI}-0.19$ to $0.05, p$ value $0.267)$.

\section{Discussion}

This study examined the feasibility of implementation of the IPCP program in three districts and evaluated its potential to increase interprofessional collaboration in caring for older people. First, our results indicate a high 


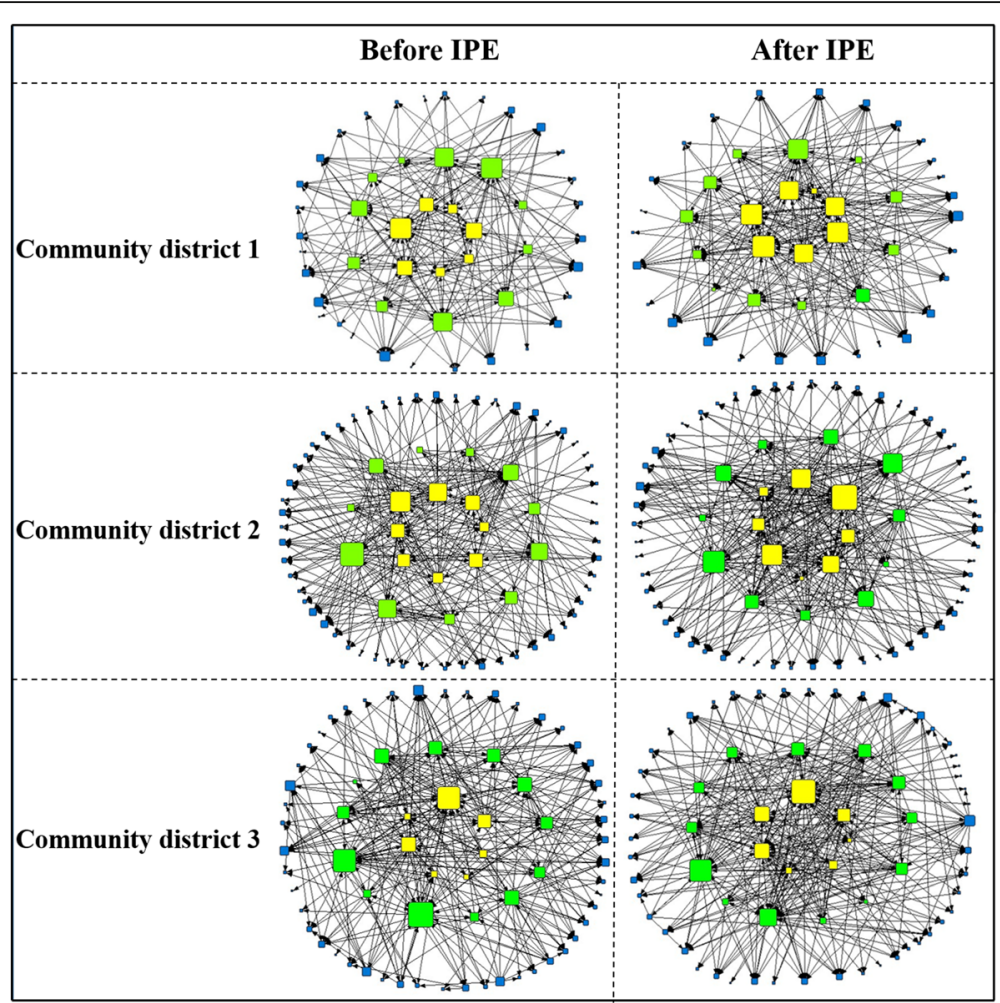

Fig. 3 Community district collaboration networks before and after the IPCP program. Yellow squares, healthcare professionals in ring 1; green squares, healthcare professionals in ring 2; blue squares, healthcare professionals in ring 3 . The larger the square the higher the number of professionals with whom the participant indicated as collaborating with regard care for older people (based on the out-degree of contacts). The black lines reflect a contact between professionals

acceptability of the IPCP program as determined by the program participants. Second, the data collection as described in the "Methods" section showed potential to reach the healthcare professionals who were not participating in the program. Third, the social network analysis showed that it was possible to measure network development for each community district in which a spillover effect was revealed. Compared with before the IPCP program, after the program, participants had a larger, more reciprocal, and more diverse interprofessional networks.

Our study showed that the IPCP program was found to be acceptable by the program participants. A more in depth understanding could be obtained when using validated questionnaires measuring levels 1,2 , and 3 of the adapted framework of Kirkpatrick for interprofessional education [22]. However, during the development process of the IPCP program, an expert team was involved to discuss the final content of the program, as previously described elsewhere [14]. The expert team did not have the scientific background to discuss the methodological rigor of the proposed evaluation but rather whether this evaluation seemed feasible for the program participants. The expert team stated that the content of the IPCP should not be at the expense of research purposes. The development team was therefore discouraged from including validated (multiple) questionnaires and therefore combined elements from the framework of Kirkpatrick for interprofessional education to one single questionnaire to examine the acceptability [22].

This study showed that it was feasible to collect social network data despite the lack of a clear network boundary. Because of scattered healthcare organizations in the districts, it was very difficult to generate a name roster of all professionals per district. These so-called "hidden," fluid networks are difficult to reach [23], and it may mean that we did not include all potential professionals in the districts. However, by combining the snowball method and a fixed-list selection of names [19, 24], we sufficiently captured this "hidden" network to assess what we were interested in, namely, the feasibility of implementing an IPCP program to improve community collaboration networks.

This study showed that the interprofessional network of the participants of the IPCP program increased in size after the program. A larger network increases the likelihood of encountering actionable knowledge [25]. 


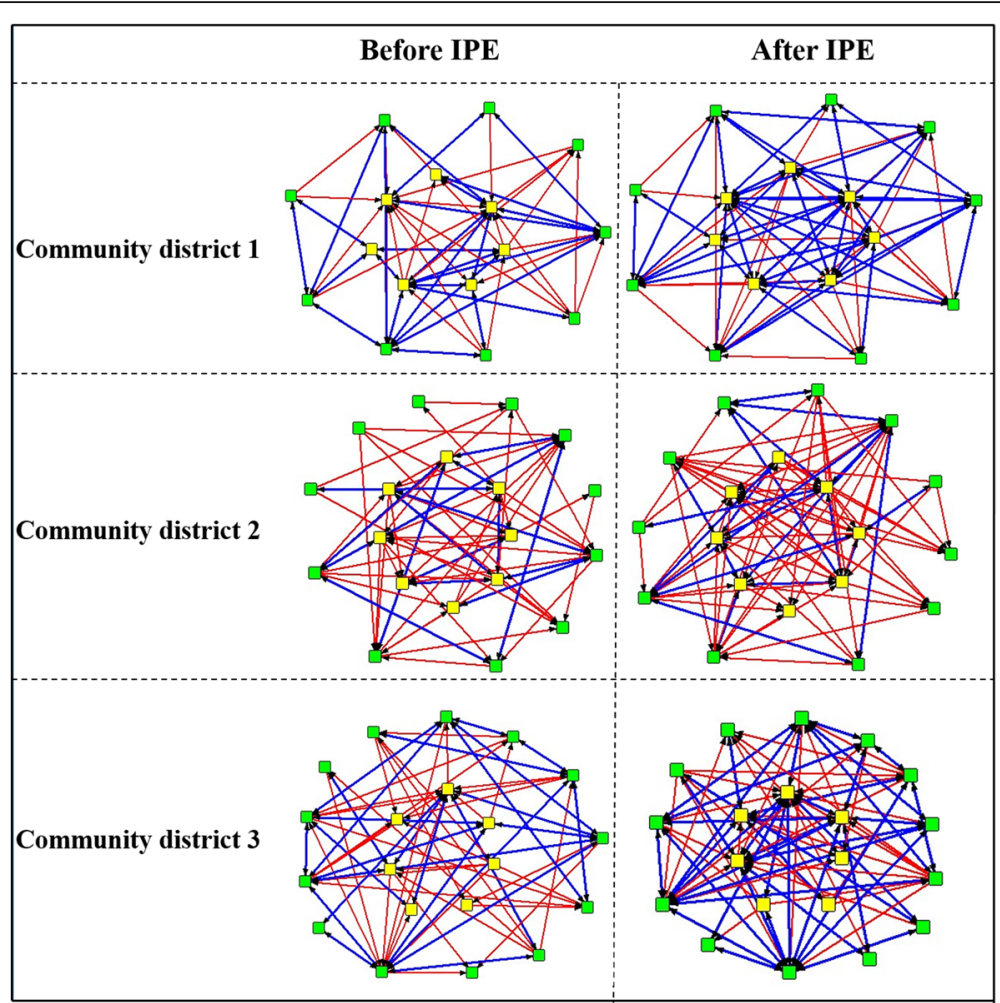

Fig. 4 Community districts' collaboration networks of reciprocal contacts. Blue lines, reciprocal contact; red lines, one-sided contact; yellow squares, healthcare professionals in ring 1; green squares, healthcare professionals in ring 2

Moreover, not only did the program participants develop their interprofessional network but, the non-program participants did as well. This spill-over phenomenon reflects findings in other fields, e.g., educational science $[26,27]$, and can be explained by the theory of "three degrees of influence" [28]. Social influence, or the effect that the words and actions of others have on our thoughts, feelings, attitudes, or behavior, has the largest effect between people who are directly connected in a network (called "1 degree of separation") [28]. Nonetheless, the theory of "three degrees of influence" asserts that social influence tends to ripple through our network to measurably influence others by up to three degrees of separation (colleague from a colleague of a colleague). While this may promote the adage "the bigger the network, the better," this saying should be interpreted carefully. The likelihood of encountering actionable knowledge by increasing one's network may be counteracted by the cost of maintaining a large network. In addition, the phrase ignores variety in the content and diversity of the network. Depending on what professionals need in caring for community-dwelling older people, some may benefit from increased network diversity while others may prefer a larger network. As such, in future work, network characteristics need to be studied in interaction. In addition, further research is necessary to understand how professionals with a large network versus those with a small network perceived the availability of actionable knowledge in their care for community-living older people.

The reciprocity in the district collaboration networks increased after the IPCP program. In other words, health and social care professionals tended to engage in more reciprocal connections after the IPCP program than before. Districts 1 and 3 showed a high increase in the reciprocity of contacts, and district 2 showed a low increase. District 2 also differed from the other districts with a lower reciprocity before the IPCP program. This study did not examine the underlying aspects for these changes. However, collaboration is a process that takes time and energy $[11,29]$. Furthermore, it is a process in which several factors play a role, such as personal skills and attitudinal aspects, but just as important is the context in which professionals work together, that it is clear and balanced [29]. In addition, after the IPCP program, healthcare professionals in all three districts showed an increase in network diversity, as their networks consisted of multi-disciplinary professionals from the IPCP as well as outside the IPCP program. Network diversity is linked to opportunities for improvement as one can tap into different sources of expertise and experiences when framing complex care needs for community-living older 
people [30]. Although there was an increase in diversity, after the IPCP, the three community districts still only utilized $32-42 \%$ of the potential diversity in their network. One explanation could be that collaboration between professionals is still based on disorders that require specialist care instead of more integral and wellness-oriented care [31,32].

In this study, the terms "collaboration" and "value" were not explicitly defined. The researchers have consciously made this choice because how professionals perceive and define collaboration can differ. For example, some professionals can value another professional because of their accessibility while for others, the fruitfulness of their contacts, regarding care for older people, is more important. This is in line with a concept analysis of interprofessional collaboration that demonstrates that IPC is a complex concept, which continues to evolve [5]. IPC has been studied as an outcome of IPE and as an antecedent to patient and provider outcomes. WHO stated that IPE has been proven to be essential in improving dynamics in local healthcare services [33]. Furthermore, coordinated home-based care by interprofessional teams is associated with lower consumption of care [34]. However, a Cochrane review from 2017 stated that there is not sufficient evidence to draw clear conclusions on the effects of IPC interventions for interprofessional practice and health outcomes, because of the certainty of evidence from the included studies, which was judged as low to very low [35]. Despite these inconclusive results regarding interprofessional practice and health outcomes, healthcare professionals are still in need of interprofessional educational programs to guide them to overcome the difficulties encountered by health professionals when collaborating in clinical practice to provide care to older people with complex care needs [35]. The outcomes of this feasibility study provided insights to expand this program on a larger scale. Following the Medical Research Council Framework, as this program can be seen as a complex intervention that contains several interacting components [36], the next step is to evaluate the IPCP program in regard to its (cost) effectiveness. A clear conceptualization of IPC, regarding antecedents, attributes, and outcomes of IPC in the context of primary care, is therefore first necessary for understanding interprofessional collaboration within different networks and how it may be strengthened [5].

\section{Strengths and limitations}

This study is among the first that uses SNA to enrich common research methods to examine the feasibility of implementing an IPCP program. While SNA is an underused method within healthcare education and intervention design, it is a useful technique for examining how social relationships among professionals are established and evolved [37-41]. Another strength of this study is its use of different data sources (i.e., IPCP program participants as well as non-program participants) to examine the feasibility of implementing the IPCP program. This triangulation results in a low samesource and same-measurement-context (SS/SMC) bias, thereby increasing the validity of our study results $[24$, 39].

This study also has some limitations. First, the presence of a Hawthorne effect, the effect of an intervention that is solely due to intervention participation, cannot completely be excluded [42]. However, the non-program participants received no intervention, and a strong increase in contacts was also observed within this group indicating that the risk of the Hawthorne effect is limited. Moreover, the nature of this study was to examine the feasibility of implementation which is commonly done in uncontrolled settings [42]. Second, the small number of participants limits generalizability. However, a large body of research has found that SNA techniques provide a robust insight into actual social networks, as these techniques focus on relationships rather than individuals [43-47]. Third, this study observed unit nonresponse defined as missing healthcare professionals in which all outgoing contacts of a professional are missing but not the incoming contacts. Although non-response results in missed contacts for some actors, partial information on the network context of the incompletely observed professionals was available due to their responding colleagues [19]. This information was included in this study and expressed within the "Results" section as ring 3 to provide a comprehensive understanding of the collaboration networks.

\section{Conclusion}

This study showed that it was feasible to implement an IPCP program in terms of acceptability, feasibility of data collection and social network analysis, and to measure network development in order to see the potential of the IPCP program to increase interprofessional collaboration between primary healthcare professionals in caring for the older population. After the IPCP program, the program participants as well as non-program participants gained a larger more collaborative, and diverse interprofessional network in primary care, suggesting a spill-over effect of networked interventions. Future studies are needed to determine the effects of interprofessional collaboration on continuity of care as well as its cost-savings.

\section{Supplementary Information}

The online version contains supplementary material available at https://doi. org/10.1186/s40814-020-00746-3.

Additional file 1. Evaluation questions IPCP program. 


\section{Acknowledgements}

None.

\section{Authors' contributions}

LS contributed substantially to the design, acquisition of data, data analysis, drafting and revising of the article, and the final approval of the version to be published. JD contributed substantially to the design, acquisition of data revision of the article, and the final approval of the version to be published. NM contributed substantially to the design, data analysis, revision of the article, and the final approval of the version to be published. MS, NdW, and NB contributed substantially to the design, revision of the article, and the final approval of the version to be published.

\section{Funding}

This study was funded by the Netherlands Organization for Health Research and Development (ZonMw), grant number 6330009816014, within the NCEP. The funders had no role in the study design, data collection and analysis, the decision to publish, or the preparation of the manuscript.

\section{Availability of data and materials}

The datasets used and/or analyzed during the current study are available from the corresponding author on reasonable request.

\section{Ethics approval and consent to participate}

This pilot study was assessed by the Institutional Review Board of the University Medical Center Utrecht (UMCU).

\section{Consent for publication}

Not applicable

\section{Competing interests}

The authors declare that they have no competing interests.

\section{Author details}

${ }^{1}$ Research Centre for Healthy and Sustainable Living, University of Applied Sciences Utrecht, 3584 CS Utrecht, The Netherlands. 'Faculty of Health, Nutrition and Sport, The Hague University of Applied Sciences, The Hague, The Netherlands. ${ }^{3}$ Dutch Inspectorate of Education, Utrecht, The Netherlands. ${ }^{4}$ Education Center, UMC Utrecht Academy, University Medical Center Utrecht, 3508 GA Utrecht, The Netherlands. ${ }^{5}$ Department of General Practice, Division Julius Center for Health Sciences and Primary Care, University Medical Center Utrecht, Utrecht, The Netherlands. ${ }^{6}$ Department of Nursing Science, Julius Center for Health Sciences and Primary Care, University Medical Center Utrecht, Utrecht, The Netherlands.

\section{Received: 9 March 2020 Accepted: 15 December 2020} Published online: 06 January 2021

\section{References}

1. World Health Organization. Framework for action on interprofessional education and collaborative practice. Geneva: World Health Organization; 2010. http://www.who.int/iris/handle/10665/70185. Accessed 5 Mar 2020.

2. NIVEL. Zorgregistraties eerste lijn. Chronische ziekten en multimorbiditeit [Chronic diseases and multimorbidity]. Utrecht: NIVEL; 2016. https://www. volksgezondheidenzorg.info/onderwerp/chronische-ziekten-enmultimorbiditeit/cijfers-context/huidige-situatie\#node-prevalentiemultimorbiditeit-naar-aantal-chronische-ziekten. Accessed 5 Mar 2020.

3. Van Kempen JA, Robben SH, Zuidema SU, Rikkert MGO, Melis RJ, Schers HJ. Home visits for frail older people: a qualitative study on the needs and preferences of frail older people and their informal caregivers. Br J Gen Pract. 2012;62(601):554-60.

4. NZa. Monitor Zorg voor Ouderen [Monitoring care for older people] Utrecht: Nederlandse Zorgautoriteit; 2018. https://puc.overheid.nl/nza/doc/ PUC_234967_22/1/. Accessed 5 Mar 2020.

5. Bookey-Bassett S, Markle-Reid M, Mckey CA, Akhtar-Danesh N. Understanding interprofessional collaboration in the context of chronic disease management for older adults living in communities: a concept analysis. J Adv Nurs. 2017:73(1):71-84.

6. Sørensen M, Stenberg U, Garnweidner-Holme L. A scoping review of facilitators of multi-professional collaboration in primary care. Int J Integr Care. 2018;18(3):13.
7. Hofhuis J, Mensen M, ten Den L, van den Berg A, Koopman-Draijer M, Smits C, de Vries S. Succesfactoren voor Interprofessioneel Samenwerken in de Wijk: een kwantitatief onderzoek onder Nederlandse zorg- en welzijnsprofessionals [Success factors for interprofessional collaboration in the community: a qualitative study among Dutch health- and social care workers]. Zwolle: Hogeschool Windesheim; 2015.

8. Reeves S, Fletcher S, Barr H, Birch I, Boet S, Davies N, Kitto S. A BEME systematic review of the effects of interprofessional education: BEME Guide No. 39. Med Teach. 2016:38(7):656-68.

9. Reeves S, Palaganas J, Zierler B. An updated synthesis of review evidence of interprofessional education. J Allied Health. 2017:46(1):56-61.

10. CAIPE - Centre for the Advancement of Interprofessional Education. 2016 https://www.caipe.org/. Assessed 5 Mar 2020.

11. American Geriatric Society. Position statement on interdisciplinary team training in geriatrics: an essential component of quality healthcare for older adults. J Am Geriatr Soc. 2014;62(5):961-5.

12. Ploeg J, Markle-Reid M, Fisher A, Bookey-Bassett S, Chambers T, Kennedy L, Dufour S. An exploration of experts' perceptions on the use of interprofessional education to support collaborative practice in the care of community-living older adults. J Interprof Care. 2017;31(5):638-47.

13. Oeseburg B, Hilberts $R$, Luten TA, van Etten AV, Slaets JP, Roodbol PF. Interprofessional education in primary care for the elderly: a pilot study. BMC Medical Education. 2013;13(1):161.

14. Smit LC, Dikken J, van Wijk M, Pool IA, Schuurmans MJ, de Wit NJ, et al. The methodological development of an interprofessional educational programme to provide proactive integrated care for elders. JRIPE. 2020;9(2): $1-25$

15. O'Keefe M, Henderson A, Chick R. Defining a set of common interprofessional learning competencies for health profession students. Med Teach. 2017:39(5):463-8.

16. Liu Q, Peng W, Zhang F, Hu R, Li Y, Yan W. The effectiveness of blended learning in health professions: systematic review and meta-analysis. J Med Internet Res. 2016;18(1):2.

17. Barr H, Koppel I, Reeves S, Hammick M, Freeth D. Effective interprofessional education. Argument, assumption \& Evidence. London: Blackwell Publishing: 2005

18. Reagans R, Zuckerman EW. Networks, diversity, and productivity: the social capital of corporate R\&D teams. Organ Sci. 2001;12(4):502-17.

19. Borgatti SP, Everett MG, Johnson JC. Analyzing social networks. London: Sage Publications; 2013.

20. Borgatti SP, Everett MG, Freeman LC. UCINET. In: Alhajj R, Rokne J, editors. Encyclopedia of Social Network Analysis and Mining. New York, NY: Springer; 2014.

21. Huisman M. Imputation of missing network data: Some simple procedures. J Soc Struct. 2009:10(1):1-29.

22. Reeves S, Barr H. Twelve steps to evaluating interprofessional education. Journal of Taibah University Medical Sciences. 2016;11(6):601-5.

23. Salganik M, Heckathorn DD. Sampling and estimation in hidden populations using respondent-driven sampling. Soc Methodol. 2004;34:193-239.

24. Carolan BV. Social network analysis and education: theory, methods, and applications. Thousand Oaks: Sage; 2014.

25. Cross R, Sproull L. More than an answer: information relationships for actionable knowledge. Organ Sci. 2004:15(4):446-62.

26. Van Waes S, De Maeyer S, Moolenaar NM, Van Petegem P, Van den Bossche P. Strengthening networks: a social network intervention among higher education teachers. Learn Instr. 2018:53:34-49.

27. Blume BD, Ford JK, Baldwin TT, Huang JL. Transfer of training: a metaanalytic review. JOM. 2010;36(4):1065-105.

28. Christakis NA, Fowler JH. Connected: the surprising power of our social networks and how they shape our lives. Boston: Little, Brown and Company; 2009.

29. Kluft M. Samenwerken in de wijk - tien vragen rondom de samenwerking tussen sociale wijkteams en andere professionals. WWorking together in the neighborhood - ten questions about the collaboration between social neighborhood teams and other professionals]. Utrecht: Movisie; 2016. Accessed 5 Mar 2020.

30. Kilduff $M$, Krackhardt D. Bringing the individual back in: a structural31. analysis of the internal market for reputation in organizations. Acad Manage J. 1994;37(1):87e108

31. Baldwin DC. Territoriality and power in the health professions. J Interprof Care. 2007;21(1):97-107. 
32. Supper I, Catala O, Lustman M, Chemla C, Bourgueil Y, Letrilliart L. Interprofessional collaboration in primary healthcare: a review of facilitators and barriers perceived by involved actors. J Public Health. 2015;37(4):716-27.

33. WHO. Interprofessional collaborative practice in primary healthcare: nursing and midwifery perspectives. Hum Resour Health Obs. 2013;24:2-16.

34. Stall N, Nowaczynski M, Sinha SK. Systematic review of outcomes from home-based primary care programs for homebound older adults. J Am Geriatr Soc. 2014;62:2243-51.

35. Reeves S, Pelone F, Harrison R, Goldman J, Zwarenstein M. Interprofessional collaboration to improve professional practice and healthcare outcomes. Cochrane Database Syst Rev. 2017;(6):CD000072.

36. Craig P, Dieppe P, Macintyre S, Michie S, Nazareth I, Petticrew M, et al. Developing and evaluating complex interventions: the new medical research council guidance. BMJ. 2008:337:a1655.

37. Parnell JM, Robinson JC. Social network analysis: presenting an underused method for nursing research. J Adv Nurs. 2018;74:1310-8.

38. Benítez-Andrades J, Rodríguez-González A, Benavides C, Sánchez-Valdeón L, García I. A semantic social network analysis tool for sensitivity analysis and what-if scenario testing in alcohol consumption studies. Int J Environ Res Public Health. 2018;15(11):2420

39. Benton DC, Pérez-Raya F, Fernández-Fernández MP, González-Jurado MA. A systematic review of nurse-related social network analysis studies. Int Nurs Rev. 2015;62(3):321-39.

40. Pow J, Gayen K, Elliott L, Raeside R. Understanding complex interactions using social network analysis. J Clin Nurs. 2012;21(19 pt20):2772-9.

41. Smit LC, Dikken J, Schuurmans MJ, de Wit NJ, Bleijenberg N. The value of social network analysis for developing and evaluating complex health care interventions: a scoping review. BMJ Open. 2020; In Press.

42. Green L, Glasgow RE. Public health asks of systems science: to advance our evidence-based practice, can you help us get more practice based evidence? Am J Public Health. 2006;96:406-9.

43. Hommes J, Rienties B, de Grave W, Bos G, Schuwirth L, Scherpbier A. Visualising the invisible: a network approach to reveal the informal social side of student learning. Adv Health Sci Educ. 2012;17(5):743e757.

44. Curşeu PL, Janssen S, Raab J. Connecting the dots: social network structure, conflict, and group cognitive complexity. High Educ. 2012;63(5):621e629.

45. Daly AJ, Finnigan KS. A bridge between worlds: understanding network structure to understand change strategy. J Educ Change. 2010;11(2):111-38.

46. Daly AJ, Moolenaar NM, Bolivar JM, Burke P. Relationships in reform: the role of teachers' social networks. JEA. 2010;48(3):359e391.

47. Borgatti SP, Cross R. A relational view of information seeking and learning in social networks. Manag Sci. 2003;49(4):432e445.

\section{Publisher's Note}

Springer Nature remains neutral with regard to jurisdictional claims in published maps and institutional affiliations.

Ready to submit your research? Choose BMC and benefit from:

- fast, convenient online submission

- thorough peer review by experienced researchers in your field

- rapid publication on acceptance

- support for research data, including large and complex data types

- gold Open Access which fosters wider collaboration and increased citations

- maximum visibility for your research: over $100 \mathrm{M}$ website views per year

At $\mathrm{BMC}$, research is always in progress.

Learn more biomedcentral.com/submissions 